\title{
BDVI, Rat Strain
}

National Cancer Institute

\section{Source}

National Cancer Institute. BDVI, Rat Strain. NCI Thesaurus. Code C14386.

About $4 \%$ of spontaneous peripheral nerve tumors, with cystic schwannomas being the most frequent type. 24 spontaneous and 28 ethylnitrosourea-induced tumors has been described by Turusov and Cabral, (1994). 